\title{
AUDIT REPORT LAG E EXPERTISE DA FIRMA DE AUDITORIA: UMA ANÁLISE COM EMPRESAS LISTADAS NA BM\&FBOVESPA
}

\author{
Rita de Cássia Correa Pepinelli Camargo ${ }^{1}$ \\ Leonardo Flach ${ }^{2}$
}

Resumo: Esta pesquisa tem por objetivo identificar se as empresas auditadas por uma firma de auditoria com expertise no setor auditado possuem um Audit Report Lag (ARL) menor do que o das demais. A importância desta investigação reside no fato de que a redução do ARL possibilita a divulgação das demonstrações contábeis de forma mais tempestiva aos usuários. A pesquisa contribui com a literatura no sentido de apresentar evidências iniciais de que a expertise da firma de auditoria está associada à diminuição do ARL das empresas brasileiras listadas na BM\&FBOVESPA, de forma similar ao encontrado por estudos desenvolvidos em outros países (Habib \& Bhuiyan, 2011; Mai \&Trung, 2014). O delineamento metodológico desta pesquisa baseou-se na análise de regressão múltipla com uma amostra formada por empresas do índice IBrX100 da BM\&FBOVESPA. A variável dependente, ARL, foi testada com uma medida de expertise da firma de auditoria no setor, controlando determinantes já conhecidos do ARL. Os resultados apontam que empresas auditadas por firmas de auditoria com expertise no setor possuem um ARL de até 15 dias a menos, quando comparado às empresas auditadas por firmas sem esta característica. Quanto as variáveis de controle, observou-se que empresas maiores, que pertencem ao setor de materiais básicos e de tecnologia da informação tendem a apresentar ARLs menores. Por outro lado, empresas com prejuízos demoram, em média, oito dias a mais para receber o parecer. $\mathrm{O}$ ARL também foi maior para empresas que possuem controle governamental, pertencem ao setor de construção e transporte, possuem maiores índices de liquidez corrente e com maiores honorários pagos aos auditores.

Palavras-chave: Audit report lag. Auditoria. Expertise. 


\section{AUDIT REPORT LAG AND AUDIT FIRM EXPERTISE: AN ANALYSIS IN TRADED COMPANIES ON THE SÃO PAULO STOCK EXCHANGE}

Abstract: This study seeks to determine whether companies audited by a firm with expertise in a particular industry display a shorter Audit Report Lag (ARL) than their counterparts. The importance of this investigation is based on the fact that reductions in ARL allow for the timelier disclosure of accounting reports to users. The research contributes to the literature by presenting initial evidence that the expertise of the audit firm in a particular industry is associated with decreased ARL of Brazilian companies listed on the São Paulo Stock Exchange, similar to that found by studies developed in other countries (Habib \& Bhuiyan, 2011; May \& Trung, 2014). The analysis was based on multiple regression with a sample composed by companies listed in $\mathrm{IBrX} 100$ index of São Paulo Stock Exchange. The dependent variable, ARL, was tested with an expertise measure of the audit firm in the industry, controlling determinants of ARL. The results show that companies audited by audit firms with expertise in their sector display an ARL of up to 15 days shorter than others do. Larger companies operating in the basic materials and information technology industries also tend to have shorter ARLs. Conversely, companies reporting losses in the period take, on average, eight days longer to receive the auditor's opinion. ARL was also shown to be greater in companies subject to government control and those pertaining to the construction and transport industries, along with those reporting higher current liquidity ratios and paying higher fees to their audit firms. Keywords: Audit report lag. Auditing. Expertise. 


\section{INTRODUÇÃO}

sta pesquisa contribui com a literatura de ARL no sentido de apresentar evidências iniciais de que a - expertise da firma de auditoria possui associação com a diminuição do ARL das empresas brasileiras. O Audit Report Lag (ARL) possui uma relação estreita com a tempestividade na divulgação das informações contábeis. Considerando que os relatórios financeiros são publicados somente após a emissão do relatório de auditoria, maiores ARLs resultam no retardamento da divulgação destes relatórios para os investidores; consequentemente, podem provocar a diminuição da eficiência informacional dos mercados (Lee et al., 2009), uma vez que a tempestividade, que é uma das características qualitativas de melhoria da informação contábil-financeira (Comitê de Pronunciamentos Contábeis [CPC], 2011), e consiste em disponibilizar a informação para os usuários a tempo de influenciar suas decisões acaba não sendo atingida. Chambers e Penman (1984) apontam que os investidores entendem como um sinal de más notícias o fato das empresas não publicarem tempestivamente seus relatórios contábeis e que, por sua vez, as empresas que publicam relatórios financeiros mais tarde do que o esperado acabam incorrendo em retornos anormais negativos.

Devido a isto, vários estudos realizados em países diferentes, se propuseram a identificar variáveis que poderiam influenciar o aumento ou diminuição do ARL. Estes estudos se concentraram principalmente em características da empresa auditada, como tamanho, complexidade, capacidade financeira, ocorrências de prejuízos, bem como em algumas características da firma de auditoria, como o fato de ser (ou não) uma Big Four, ou de emitir um relatório modificado (Ashton, Willingham, \& Elliott, 1987; Jaggi \& Tsui, 1999; Lee et al., 2009; Leventis, Weetman, \& Caramanis, 2005; Newton \& Ashton, 1989; Ng \& Tai, 1994).

As pesquisas realizadas com amostras de empresas brasileiras constaram que o ARL aumenta, por exemplo, em função da complexidade da empresa auditada, do risco, do tipo do parecer ou da ocorrência de prejuízos no período e diminui em função do tamanho da empresa auditada e da presença de um comitê de auditoria (Camargo, 2012; Pereira \& Costa, 2012).

Habib e Bhuiyan (2011) e Mai e Trung (2014) investigaram o efeito da expertise da firma de auditoria em um determinado setor auditado sobre o ARL. Os autores encontraram que a expertise tem um efeito de diminuição do ARL das empresas investigadas. Estes resultados auxiliam na busca de estratégias para o aumento da tempestividade da informação contábil atrelada a finalização dos relatórios de auditoria e consequentemente da divulgação dos relatórios financeiros.

O presente estudo segue a linha de Habib e Bhuiyan (2011) e Mai e Trung (2014) de forma que o objetivo da pesquisa é identificar se as empresas auditadas por uma firma de auditoria com expertise no setor auditado possuem um ARL menor do que o das demais. Neste sentido, a pesquisa visa responder a seguinte questão: Qual a relação entre o ARL e a expertise da firma de auditoria no setor auditado?

Espera-se que a contratação de uma firma de auditoria com expertise no setor resulte em um ARL mais curto. Primeiro, devido à redução de tempo que os auditores experts precisariam para se familiarizar com os sistemas de relatórios financeiros das empresas auditadas em relação a auditores sem esta característica. Segundo, porque é provável que auditores experts, com sólido conhecimento no 
setor, sejam mais ágeis para resolver problemas contábeis complexos em comparação com os demais auditores (Habib \& Bhuiyan, 2011).

Adicionalmente, o efeito da expertise da firma de auditoria no setor sobre a diminuição do ARL, pode ser válido, conforme Mai e Trung (2014) demonstraram em sua pesquisa, para países em que o rodízio de auditoria é obrigatório, como é o caso do Brasil (Instrução CVM no 308/99 e 509/11), uma vez que esta característica da firma de auditoria pode atenuar o impacto do rodízio no ARL. Em geral, nos anos iniciais de relacionamento entre auditor e empresa auditada os trabalhos da firma de auditoria levam um tempo maior, pois é necessário se familiarizar com as operações e os sistemas de relatórios financeiros utilizados pelo cliente. Neste caso, a contratação de auditores com expertise no setor, que possuem conhecimento especializado do setor do cliente, pode ser capaz de reduzir o efeito negativo da falta de conhecimento sobre as operações do cliente nos anos iniciais de relacionamento e, por sua vez, diminuir o ARL.

Habib e Bhuiyan (2011) encontraram evidências na Nova Zelândia que empresas auditadas por firmas de auditoria experts no setor têm ARLs mais curtos. Mai e Trung (2014) constaram que um tempo menor de relacionamento entre firma de auditoria e empresa auditada que, em geral, provocaria um ARL maior é atenuado pela contratação de uma firma de auditoria com expertise no setor. Esta pesquisa traz evidências iniciais que o ARL de empresas brasileiras listadas na BM\&FBOVESPA é diminuído em função da contratação de um auditor com expertise no setor.

A amostra selecionada para realização da pesquisa engloba as empresas listadas na BM\&FBOVESPA participantes do índice IBrX100 no ano de 2013. Para mensuração da expertise foi considerado o valor dos honorários recebidos pelas firmas de auditoria no setor seguindo a métrica utilizada por Habib e Bhuiyan (2011). Com o controle dos determinantes de ARL, já reconhecidos pela literatura, encontrou-se que o ARL de empresas que contrataram firmas de auditoria com expertise diminui em até 15 dias. Os resultados relacionados às variáveis de controle indicam que possuem ARL's menores, empresas maiores, classificadas nos setores de materiais básicos e tecnologia da informação. Por outro lado, o aumento do ARL está relacionado à apresentação de prejuízos pela empresa auditada, ao controle governamental, aos maiores valores de honorários pagos aos auditores, a maiores índices de liquidez corrente e aos setores de construção e transporte. Os resultados estimados pelo método de mínimos quadrados ordinários (MQO) foram similares a estimações realizadas como análise de sensibilidade e robustez, utilizando a regressão Tobit e a regressão quantílica, o que reitera a robustez dos resultados apresentados.

No tópico a seguir é apresentado o referencial teórico e o desenvolvimento da hipótese de pesquisa. Na sequência são expostos os procedimentos metodológicos, os resultados, a análise de sensibilidade e a conclusão da pesquisa.

\section{REFERENCIAL TEÓRICO}

A teoria da agência expõe que diferentes motivações e a assimetria de informação existente entre administradores e proprietários (acionistas) implica a necessidade da contratação de auditores independentes para a redução do custo de agência e inibição de comportamentos oportunistas dos gestores (Jensen \& Meckling, 1976). Jensen e Meckling (1976) apontam que o monitoramento efetuado pela firma de auditoria somente aumentará o valor da empresa, se o auditor relatar as brechas encontradas nos contratos entre gestores e acionistas, o que teoricamente é assegurado pela própria definição de independência do auditor (Watts \& Zimmerman, 1983). 
Nesta discussão está inserida a necessidade da realização da auditoria com tempestividade, pois da sua conclusão depende a publicação dos relatórios contábeis. A respeito da tempestividade, uma das características observáveis na auditoria, o ARL, tem sido estudado em vários países. Em geral, as conclusões dos estudos apontam que empresas maiores tendem a receber seus pareceres em um menor espaço de tempo (Habib \& Bhuiyan, 2011), tendo em vista a probabilidade maior de possuírem sistemas contábeis e financeiros mais organizados, além de controles internos mais eficazes. Por outro lado, empresas com prejuízos ou com itens extraordinários no exercício, ou ainda com maior complexidade, como a existência de filiais e a necessidade de consolidação dos relatórios contábeis, tendem a apresentar ARLs mais longos (Habib \& Bhuiyan, 2011).

Ashton et al. (1987) encontraram em sua pesquisa que empresas maiores (InReceitas), com complexidade maior (número de subsidiárias) demoravam mais tempo para receber seus pareceres. Por outro lado, empresas com qualidade em seus controles internos, menor quantidade de trabalho dos auditores após o encerramento do exercício social e que possuíam capital aberto, apresentavam ARLs menores.

No Canadá, Newton e Ashton (1989) constataram que empresas maiores, com encerramento contábil em dezembro e com uma maior variação positiva nos lucros, possuíam um ARL menor. Adicionalmente, concluíram que empresas que divulgam itens extraordinários, atuam no setor não financeiro e são auditadas por firmas que possuem um grau mais elevado de estruturação tecnológica possuíam ARLs maiores.

Ng e Tai (1994), em Hong Kong, encontraram alguns resultados similares a Newton e Ashton (1989). Constaram que empresas que possuem encerramento contábil em dezembro, divulgam itens extraordinários e maior quantidade de subsidiárias, possuem ARLs maiores. Além disso, empresas maiores demoram menos tempo para receber seus pareceres.

Ainda em Hong Kong, Jaggi e Tsui (1999) encontraram que empresas que possuem maiores ARLs têm, em geral, um maior risco financeiro e são auditadas por firmas de auditoria que utilizam abordagens mais estruturadas.

Leventis et al. (2005) investigaram empresas da Bolsa de Valores de Atenas e encontraram que menores ARLs estão relacionados a firmas de auditoria Big- $\mathrm{N}$, que cobram maiores honorários de auditoria, enquanto maiores ARLs estão associados ao número de modificações no parecer de auditoria, divulgação de itens extraordinários e expressões características de incertezas nos pareceres.

Lee et al. (2009) constataram que quanto mais longo o tempo de relacionamento entre auditor e auditado e a prestação de serviços de não auditoria pelos auditores contribuem para diminuição do ARL. De acordo com os autores, estas características contribuem para a eficiência da auditoria e para que os auditores emitam pareceres de forma mais tempestiva. Também demoram mais para receber $o$ parecer as empresas com dificuldades financeiras, com maiores números de segmentos de negócios, que pagam honorários anormais de auditoria, com prejuízos no ano analisado e com recebimento de parecer modificado. De forma inversa, o ARL é menor para as empresas que são auditadas por firmas de auditoria Big-N, que são maiores pelo valor do ativo e que divulgam lucros inesperados no período.

No Brasil, Pereira e Costa (2012) encontraram evidências de um ARL menor para empresas maiores, e um ARL maior para empresas que receberam um parecer com ressalva ou apresentaram prejuízo no exercício. Adicionalmente, Camargo (2012) encontrou que maiores ARLs estão relacionados a empresas com maior risco, com prejuízos no período analisado, que possuem subsidiárias controladas, com controle público e que pertencem ao setor de consumo não cíclico. Já as empresas que possuem um comitê de auditoria e um índice maior de liquidez corrente apresentaram, em geral, ARLs menores. 
De forma resumida, os estudos relacionados ao ARL têm constatado que algumas características relacionadas com as empresas auditadas, tais como o tamanho, contribuem para a diminuição do ARL. Algumas pesquisas constaram que empresas auditadas por firmas de auditoria Big-N também tendem a receber mais cedo os seus pareceres. De acordo com Habib e Bhuiyan (2011), além da firma de auditoria pertencer ao grupo das Big-N outra característica que pode diminuir o ARL é o fato de possuir expertise no setor. Para os autores, considerando que auditores experts desenvolvem conhecimentos específicos do setor, o conhecimento e experiência adquiridos permitem que eles se familiarizem de forma mais rápida com as operações dos clientes. Assim, espera-se que eles sejam capazes de concluir a auditoria mais cedo do que outros auditores sem esta característica.

Habib e Bhuiyan (2011), em sua pesquisa realizada com empresas da Nova Zelândia, encontraram evidências que empresas auditadas por firmas de auditoria com expertise no setor possuem ARLs mais curtos. Mai e Trung (2014), com uma amostra de empresas norte-americanas, constataram que empresas com um tempo mais curto de relacionamento entre auditor e auditado, que provocaria, em geral, um ARL maior, tem o tempo para emissão do parecer reduzido pela contratação de uma firma de auditoria com expertise no setor.

Os resultados de Mai e Trung (2014) indicam que firmas de auditoria com expertise no setor, são capazes de reduzir o efeito negativo da falta de conhecimento sobre as operações do cliente nos anos iniciais de relacionamento. Assim, considerando as constatações de Lee et al. (2009) que argumentam que as trocas de auditores em função de rodízios obrigatórios, como no caso do Brasil, ocasionam o aumento da ineficiência informacional, através de um maior atraso na divulgação dos relatórios financeiros em função de um maior ARL, a contratação de auditores com expertise no setor poderia atenuar, em média, o tempo para o recebimento do parecer de auditoria. Neste sentido, tem-se a seguinte hipótese de pesquisa:

H1. Empresas auditadas por firmas de auditoria com expertise no setor possuem em média um menor ARL do que empresas auditadas por firmas de auditoria sem esta característica.

\section{PROCEDIMENTOS METODOLÓGICOS}

\subsection{SELEÇÃO DA AMOSTRA E COLETA DE DADOS}

A amostra da pesquisa é composta pelas empresas listadas na BM\&FBOVESPA pertencentes ao índice $\mathrm{IBrX100}$. Foi escolhido o índice $\mathrm{IBrX100}$, pois este engloba as empresas com maior volume de negociação na BM\&FBOVESPA, sendo possível que estas empresas busquem melhores auditorias, priorizando desta forma, firmas de auditoria com expertise no setor. Foram excluídas as empresas do setor financeiro por apresentarem especificidades, como regulamentações específicas no que tange aos relatórios financeiros, controles internos e auditoria (por exemplo, os Acordos de Basiléia e os normativos do Banco Central do Brasil - BACEN), bem como pelo forte enforcement. Além destes fatores, especificidades financeiras destas empresas, como medidas de liquidez (utilizadas como variáveis independentes) poderiam enviesar as análises. Este procedimento resultou em uma amostra com 77 empresas. A coleta de dados foi realizada considerando como base o ano de 2013. Entende-se que a seleção de empresas pertencentes ao índice IBrX100 e na forma de cross-section não invalida a relevância da pesquisa, por se tratar de uma investigação inicial da relação entre ARL e expertise da firma de auditoria, até então não realizada em pesquisas anteriores no Brasil. Pesquisas anteriores no 
Brasil sobre o tema têm apresentado evidências relevantes sobre os determinantes do ARL (Camargo, 2012; Pereira \& Costa, 2012), sem contudo, investigar especificamente sua relação com a expertise da firma de auditoria no setor, foco desta pesquisa. Desta forma, entende-se que a amostra e o período selecionado podem auxiliar em uma compreensão inicial, isto é, em um primeiro estágio, sobre a relação entre a expertise da firma de auditoria e o tempo para emissão do parecer, considerando que a probabilidade de modificação de firmas de auditoria é baixa de um ano para o outro, salvo em função do rodízio obrigatório, o que não é o caso para o ano escolhido.

Alguns dados foram coletados pela base de dados Economatica ${ }^{\oplus}$, outros coletados manualmente pelos Formulários de Referência (FR) e pelas Demonstrações Financeiras Padronizadas (DFP) arquivadas no sítio da Comissão de Valores Imobiliários (CVM). São exemplos de informações que foram coletadas manualmente: a data de emissão do relatório de auditoria divulgado nas DFP para composição da variável ARL e o valor dos honorários de auditoria divulgado no FR para mensuração da expertise da firma de auditoria no setor.

A amostra inicial era de 77 empresas, mas cinco empresas foram excluídas da pesquisa: uma empresa foi excluída por informar dados de honorários iguais aos informados pela matriz, impossibilitando desmembrar estes valores entre as empresas; três por serem as únicas empresas pertencentes ao setor e impossibilitarem a mensuração da expertise; e uma por possuir um ARL considerado como outlier para amostra (três vezes maior que a média de ARL das demais empresas), o que poderia enviesar a análise. Reforça-se que a exclusão do outlier foi realizada, pois se tratava de uma única observação que diferentemente das demais empresas da amostra, embora não dispensada do cumprimento, não vem seguindo as normatizações impostas pela CVM e pela legislação societária quanto aos prazos de entrega das DFP's. Deste modo, a inclusão desta empresa ocasionaria uma distorção nos resultados da pesquisa, por incorporar na amostra uma empresa com características que não representam a normalidade do fenômeno investigado, que diz respeito à tempestividade da divulgação de relatórios financeiros. Portanto, a amostra final é composta por 72 empresas.

A mensuração da expertise da firma de auditoria nos setores das empresas pertencentes à amostra foi realizada conforme a métrica definida na seção 3.2.2. Os setores considerados para a mensuração da expertise são decorrentes da classificação da BM\&FBOVESPA denominada "subsetor". Por exemplo, dentro do setor de "Construção de Transporte", há os subsetores de "Construção e Engenharia" e"Transporte". Neste sentido, identificou-se a expertise da firma de auditoria com base nos honorários pagos pelas empresas que compõem o subsetor de "Construção e Engenharia" e "Transporte". O resultado desta análise é apresentado na Tabela 1.

Salienta-se que em setores nos quais havia empresas que não divulgaram o valor dos honorários pagos aos auditores, a mensuração da expertise foi realizada desconsiderando as mesmas. Neste caso, esta constitui em uma limitação da pesquisa.

\subsection{MODELO E VARIÁVEIS ESTUDADAS}

\subsubsection{Modelo estimado}

Para testar $\mathrm{H} 1$ e investigar a associação entre ARL e expertise no setor da firma de auditoria foram utilizados um teste de diferença de médias (Teste T de Student) e o seguinte modelo de regressão linear múltipla, estimado pelo método dos mínimos quadrados ordinários (MQO): 
$A R L=\alpha+\beta 1$ LnREC $+\beta 2$ LnLIQC $+\beta 3$ LnTAUDFEES $+\beta 4$ YEND $+\beta 5$ LOSS $+\beta 6$ COMIT $+\beta 7$ SUB $+\beta 8$ TEN $+\beta 9$ MODIF $+\beta 10$ CONTR $+\beta 11$ SET $+\beta 12$ SPEC $+\varepsilon$,

Em que:

$A R L=$ Tempo para emissão do relatório de auditoria;

LnREC = Log Natural da Receita de Vendas no período;

LnLIQC = Log Natural do índice Liquidez Corrente no período;

LnTAUDFEES = Log Natural do Total dos Honorários de Auditoria no período;

YEND = Encerramento do exercício social em 31/12 (dummy);

LOSS = Prejuízo no exercício (dummy);

COMIT = Existência de Comitê de auditoria (dummy);

SUB = Existência de Subsidiárias (dummy);

TEN = Tempo de relacionamento entre auditor e auditada (dummy);

MODIF = Parecer Modificado (dummy);

CONTR = Controle Governamental (dummy);

SET = Setor de atuação da empresa (dummy);

SPEC $=$ Firma de auditoria com expertise (dummy); $\mathrm{e}$,

$\varepsilon=$ Termo de erro da regressão.

Para verificação da adequação do modelo estimado pelo método MQO foram realizados os testes de normalidade, ausência de autocorrelação serial nos resíduos, multicolinearidade e homoscedasticidade. O teste Kolmogorov-Smirnov não apresentou significância estatística, indicando que os resíduos do modelo seguem distribuição normal. O teste Durbin-Watson indicou a ausência de autocorrelação serial entre resíduos do modelo. Os resultados do VIF (Variance Inflation Factor) entre 1 e 2, indicam a inexistência de problemas de multicolinearidade no modelo estimado. Quanto à homoscedasticidade, o teste de Breusch-Pagan indicou a ausência de heteroscedasticidade nas observações.

\subsubsection{Mensuração da expertise no setor da firma de auditoria}

Para mensurar a expertise no setor das firmas de auditoria, Habib e Bhuiyan (2011) utilizaram a proporção de honorários de cada firma de auditoria nos setores definidos pela bolsa de valores da Nova Zelândia. A mesma medida foi adotada nesta pesquisa, porém com base na bolsa de valores do Brasil, a BM\&FBOVESPA. Desta forma, a expertise foi mensurada conforme a Equação (2).

$$
P R O P_{-} H O N_{i k}=\frac{\sum_{j=1}^{J i k} H O N_{i j k}}{\sum_{i=1}^{I k} \Sigma_{j=1}^{J i k} H_{i j k}},
$$

Nesta equação (2), HON consiste no total de honorários recebidos pela firma de auditoria; o numerador da equação compreende a soma do total de honorários Jik de todos os clientes da firma de auditoria i no setor k; o denominador da equação compreende a soma do total de honorários Jik de todos os clientes do setor $k$, somados para todas as firmas de auditoria lk.

Similar a Habib e Bhuiyan (2011) foram utilizadas duas definições para a expertise no setor. $\mathrm{Na}$ Definição (1), a firma de auditoria possui expertise no setor se tem a maior quota de mercado nos respectivos setores e se a sua quota de mercado é no mínimo dez pontos percentuais maior do que 
a da segunda colocada. Ressalta-se que nesta pesquisa, quota de mercado compreende o percentual de honorários recebidos no setor pela firma de auditoria. Na Definição (2), a firma de auditoria possui expertise no setor se possuir uma quota de mercado superior a 30\% nos respectivos setores (Reichelt \& Wang, 2010). Salienta-se que a quota de mercado da firma de auditoria foi identificada conforme explicitado na Equação 2.

A medida adotada, baseada no valor dos honorários, pode ser questionada em relação à dependência financeira das firmas de auditoria, que pode ocorrer devido aos honorários cobrados de seus clientes em seus contratos. Esta pode ser considerada uma limitação da medida adotada como proxy nesta pesquisa. No entanto, vale considerar que as responsabilidades firmadas entre firma de auditoria e empresa auditada são decorrentes da complexidade da auditoria e do compromisso financeiro firmado (contrato) e tendem a serem maiores e com consequências mais severas em relação aos contratos com valores maiores de honorários. Deve-se considerar ainda, que contratos de auditoria firmados com valores maiores de honorários, geralmente, demandam maior quantidade de treinamentos, preparação e diligências por parte da firma de auditoria, não representando apenas uma mera relação de dependência financeira.

Embora possam existir outras medidas para mensuração de expertise, a medida escolhida têm sido amplamente utilizada pela literatura (por exemplo, Habib \& Bhuiyan, 2011; Mai \& Trung, 2014; Reichelt \& Wang, 2010). Contudo, é imprescindível reconhecer que a escolha por uma definição possui limitações, uma vez que a expertise no setor não é diretamente observável, de forma que é possível que as definições utilizadas incluam ruídos de mensuração. No entanto, análises de sensibilidade realizadas em pesquisas anteriores (Habib \& Bhuiyan, 2011; Mai \& Trung, 2014; Reichelt \& Wang, 2010) demonstram que a medida adotada nesta pesquisa tem proporcionado resultados confiáveis.

\subsubsection{Variáveis investigadas}

As variáveis estudadas nesta pesquisa foram baseadas nas variáveis utilizadas no trabalho de Habib e Bhuiyan (2011) e outros estudos desenvolvidos sobre ARL. A variável dependente investigada, o ARL, compreende o número de dias entre o encerramento do exercício social e a emissão do relatório de auditoria. As variáveis independentes investigadas na pesquisa são apresentadas na Figura 1. Além das variáveis de interesse SPEC10 e SPEC30, outras variáveis de controle também são apresentadas. Uma discussão resumida sobre as variáveis de controle selecionadas e as relações esperadas com ARL é apresentada na sequência.

Figura 1: Variáveis investigadas na pesquisa

\begin{tabular}{|c|c|c|c|}
\hline Variável & SN & Descrição & Fundamentação \\
\hline \multicolumn{4}{|l|}{ Variável de interesse } \\
\hline $\begin{array}{l}\text { Expertise da firma de } \\
\text { auditoria (SPEC10) }\end{array}$ & $(-)$ & $\begin{array}{c}\text { Variável dummy que assume } 1 \\
\text { se a firma de auditoria possui } \\
\text { expertise no setor da empresa } \\
\text { auditada, cfe. definição (1), e } \\
0 \text {, caso contrário. }\end{array}$ & $\begin{array}{c}\text { (Habib \& Bhuiyan, 2011; Mai \& } \\
\text { Trung, 2014; Reichelt \& Wang, } \\
\text { 2010). }\end{array}$ \\
\hline $\begin{array}{l}\text { Expertise da firma de } \\
\text { auditoria (SPEC30) }\end{array}$ & $(-)$ & $\begin{array}{c}\text { Variável dummy que assume } 1 \\
\text { se a firma de auditoria possui } \\
\text { expertise no setor da empresa } \\
\text { auditada, cfe. definição (2), e } \\
\text { 0, caso contrário. }\end{array}$ & $\begin{array}{c}\text { (Habib \& Bhuiyan, 2011; Mai \& } \\
\text { Trung, 2014; Reichelt \& Wang, } \\
\text { 2010). }\end{array}$ \\
\hline \multicolumn{4}{|l|}{ Variáveis de Controle } \\
\hline Variável & SN & Descrição & Fundamentação \\
\hline
\end{tabular}




\begin{tabular}{|c|c|c|c|}
\hline $\begin{array}{l}\text { Tamanho da empresa } \\
\text { auditada (LnREC) }\end{array}$ & $(-)$ & $\begin{array}{l}\text { Logaritmo Natural da Receita } \\
\text { de Vendas }\end{array}$ & $\begin{array}{c}\text { (Bruynseels, Knechel, \& } \\
\text { Willekens, 2011; Camargo, } \\
\text { 2012; Habib \& Bhuiyan, 2011; } \\
\text { Lee et al., 2009; Mai \& Trung, } \\
\text { 2014; Newton \& Ashton, } \\
\text { 1989; Ng \& Tai, 1994; Pereira \& } \\
\text { Costa, 2012). }\end{array}$ \\
\hline $\begin{array}{l}\text { Encerramento do exercício } \\
\text { (YEND) }\end{array}$ & $(+)$ & $\begin{array}{l}\text { Variável dummy que assume } \\
1 \text { se o final do exercício social } \\
\text { é } 31 / 12 \text { e } 0 \text {, caso contrário. }\end{array}$ & $\begin{array}{c}\text { (Ashton et al., 1987; Habib \& } \\
\text { Bhuiyan, 2011; Lee et al., 2009; } \\
\text { Mai \& Trung, 2014; Newton \& } \\
\text { Ashton, 1989; Ng \& Tai, 1994). }\end{array}$ \\
\hline Prejuízo (LOSS) & $(+)$ & $\begin{array}{c}\text { Variável dummy que assume } \\
1 \text { caso a empresa apresente } \\
\text { prejuízo no período e } 0 \text {, caso } \\
\text { contrário. }\end{array}$ & $\begin{array}{c}\text { (Camargo, 2012; Habib \& } \\
\text { Bhuiyan, 2011; Lee et al., 2009; } \\
\text { Mai \& Trung, 2014; Newton \& } \\
\text { Ashton, 1989; Pereira \& Costa, } \\
\text { 2012). }\end{array}$ \\
\hline Liquidez Corrente (LnLIQC) & $(-)$ & $\begin{array}{l}\text { Variável medida pelo } \\
\text { logaritmo do índice de } \\
\text { liquidez corrente. }\end{array}$ & (Camargo, 2012). \\
\hline Comitê de auditoria (COMIT) & $(-)$ & $\begin{array}{c}\text { Variável dummy que assume } \\
1 \text { caso a empresa possua } \\
\text { comitê de auditoria e } 0 \text {, caso } \\
\text { contrário. }\end{array}$ & (Camargo, 2012). \\
\hline Subsidiárias (SUB) & $(+)$ & $\begin{array}{c}\text { Variável dummy que } \\
\text { assume } 1 \text { caso a empresa } \\
\text { auditada possua subsidiárias } \\
\text { controladas e } 0 \text {, caso } \\
\text { contrário. }\end{array}$ & $\begin{array}{c}\text { (Ashton et al., 1987; Habib \& } \\
\text { Bhuiyan, 2011; Ng \& Tai, 1994). }\end{array}$ \\
\hline $\begin{array}{l}\text { Tempo de relacionamento } \\
\text { entre auditor e auditada (TEN) }\end{array}$ & $(-)$ & $\begin{array}{c}\text { Variável dummy que assume } \\
1 \text { para empresas que são } \\
\text { auditadas pela mesma firma } \\
\text { de auditoria por um tempo } \\
\text { igual ou superior a três anos e } \\
\text { 0, caso contrário. }\end{array}$ & $\begin{array}{l}\text { (Habib \& Bhuiyan, 2011; Lee et } \\
\text { al., 2009; Mai \& Trung, 2014) }\end{array}$ \\
\hline Parecer Modificado (MODIF) & $(+)$ & $\begin{array}{l}\text { Variável dummy que assume } 1 \\
\text { para empresas que receberam } \\
\text { pareceres com ressalva, } \\
\text { adverso ou com abstenção de } \\
\text { opinião e } 0 \text {, caso contrário. }\end{array}$ & $\begin{array}{l}\text { (Lee et al., 2009; Leventis et al., } \\
\text { 2005; Pereira \& Costa, 2012). }\end{array}$ \\
\hline Tipo de Controle (CONTR) & $(+)$ & $\begin{array}{l}\text { Variável dummy que assume } \\
1 \text { para empresas com controle } \\
\text { público e } 0 \text {, caso contrário. }\end{array}$ & (Camargo, 2012). \\
\hline Setor (SET) & $(?)$ & $\begin{array}{l}8 \text { variáveis dummy para os } \\
9 \text { setores da BM\&FBOVESPA, } \\
\text { que assume } 1 \text { se a empresa } \\
\text { pertencer ao setor e } 0 \text {, caso } \\
\text { contrário. }\end{array}$ & $\begin{array}{c}\text { (Camargo, 2012; Ng \& Tai, } \\
\text { 1994). }\end{array}$ \\
\hline $\begin{array}{l}\text { Total dos Honorários de } \\
\text { Auditoria (LnTAUDFEES) }\end{array}$ & $(-)$ & $\begin{array}{l}\text { Logaritmo natural do total de } \\
\text { honorários pagos à firma de } \\
\text { auditoria no período. }\end{array}$ & (Leventis et al., 2005) \\
\hline
\end{tabular}

Legenda: SN - Sinal Esperado. Fonte: Elaborada pelos autores.

Expertise da Firma de Auditoria (SPEC10 e SPEC30): Auditores com expertise no setor se diferenciam dos demais devido aos investimentos realizados para auditar determinado setor, como formação dos seus profissionais e aperfeiçoamento dos sistemas utilizados durantes os trabalhos (Habib \& Bhuiyan, 2011; Reichelt \& Wang, 2010). Estes custos, por sua vez, são justificados, pois podem ser recuperados por meio de mais clientes (Habib \& Bhuiyan, 2011). Considerando que os conhecimentos específicos do setor detidos pelos auditores experts, permitem que eles alcancem um nível de eficiência mais elevado, espera-se que eles sejam capazes de concluir a auditoria mais cedo do que outros auditores sem esta característica. Assim, espera-se uma relação negativa entre ARL e SPEC10 e SPEC30.

Tamanho da empresa auditada (LnREC): Entre as medidas mais comumente utilizadas como proxy para tamanho da empresa auditada está a Receita de Vendas e o Ativo Total. Em geral, os estudos demonstram que empresas maiores tendem a receber seus pareceres em um menor espaço de tempo (Habib \& Bhuiyan, 2011; Lee et al., 2009; Newton \& Ashton, 1989; Ng \& Tai, 1994; Pereira \& Costa, 2012), tendo em vista que geralmente há a propensão de possuírem sistemas contábeis e financeiros mais organizados, além de controles internos mais eficazes. Desta forma, espera-se uma relação negativa entre ARL e LnREC. 
Encerramento do exercício (YEND): Estudos como os de Ashton et al. (1987) e Newton e Ashton (1989) apontam que a data de encerramento contábil em 31/12 está relacionada a um maior ARL. A realização de auditorias em períodos em que ocorre o encerramento contábil da maior parte das empresas pode acarretar em maior carga de trabalho para os auditores ( $\mathrm{Ng} \&$ Tai, 1994). Assim, é esperado que as empresas com encerramento contábil em 31/12, o que é mais comum nas empresas listadas na BM\&FBOVESPA, possuam maiores ARLs, isto é, que ARL tenha uma relação positiva com YEND.

Prejuízo (LOSS): A existência de prejuízo no período pode fazer com que a empresa queira retardar uma má notícia, ou ainda que os auditores sejam mais cautelosos durante a realização dos trabalhos (Habib \& Bhuiyan, 2011). Em conformidade com os resultados encontrados por Camargo (2012), Habib e Bhuiyan (2011), Lee et al. (2009), Mai e Trung (2014) e Pereira e Costa (2012), espera-se uma relação positiva entre ARL e LOSS.

Liquidez Corrente (LnLIQC): Para Ireland (2003), as empresas com menor índice de liquidez podem ter maior probabilidade de receber pareceres modificados por questões de continuidade do que as demais empresas. Então, é possível que os auditores demorem mais tempo para emitir o parecer. Em linha com os resultados de Camargo (2012), espera-se uma relação negativa entre ARL e LnLIQC.

Comitê de auditoria (COMIT): Conforme argumentam Ballesta e García-Meca (2005), uma boa estrutura de governança pode auxiliar a reduzir os problemas relacionados à auditoria independente. A presença de um comitê de auditoria, conforme Camargo (2012) pode aumentar a confiabilidade em relação às demonstrações contábeis da empresa auditada. Assim, espera-se que a existência de um comitê de auditoria implantado na empresa auditada implique na redução do tempo, em média, para emissão do parecer. Neste caso, espera-se uma relação negativa entre ARL e COMIT.

Subsidiárias (SUB): Espera-se uma relação positiva entre ARL e SUB. Isto porque empresas que possuem muitas subsidiárias controladas acarretam a necessidade de maior tempo dos auditores para o exame das respectivas demonstrações, para se certificarem que todos os aspectos relevantes foram considerados nas demonstrações financeiras consolidadas da empresa auditada (Palmrose, 1986).

Tempo de relacionamento entre auditor e empresa auditada (TEN): Para ARL e TEN espera-se uma relação negativa. Considerando que um tempo maior de relacionamento entre o auditor e empresa auditada pode proporcionar existência de maior familiaridade dos auditores das operações realizadas pela empresa, seus segmentos de negócio e estratégias, e melhor conhecimento do seu sistema de controle interno, é possível que em empresas que possuam contratos com a mesma firma de auditoria por um período maior tendam a receber seus pareces em um menor tempo (Ye, Carson, \& Simnett, 2011).

Parecer Modificado (MODIF): Quando o auditor tem que emitir um parecer modificado, isto é, com ressalva, adverso ou com abstenção de opinião, é possível que o relatório demore mais tempo para ser emitido. Isto se justifica em virtude de uma possível tentativa de negociação entre o auditor e a empresa auditada, sobre as alterações necessárias nas demonstrações da empresa para evitar esta situação (Pereira \& Costa, 2012). Assim, espera-se uma relação positiva entre ARL e MODIF.

Tipo de Controle (CONTR): Camargo (2012) aponta que em empresas com controle público (governamental ou estatal), a contratação dos auditores independentes é realizada levando em consideração procedimentos formais e complexos, como a lei de licitação. Neste caso, há possivelmente uma menor pressão exercida sobre os auditores pela administração da empresa auditada para emitir o parecer em menor tempo. Isto se justifica pelo fato de o auditor geralmente possuir um contrato de prestação de serviços com uma possibilidade praticamente remota de rescisão. Desta forma, levando em consideração os resultados da pesquisa mencionada, espera-se uma relação positiva entre ARL e CONTR. 
Setor: Empresas de determinados setores podem apresentar características distintas, de modo que esta característica implique em maior ou menor tempo para receber o parecer de auditoria $(\mathrm{Ng}$ \& Tai, 1994). Neste caso, não há expectativa em relação aos sinais esperados entre ARL e os setores da BM\&FBOVESPA.

Total dos Honorários de Auditoria (LnTAUDFEES): Os resultados de Leventis et al. (2005) apontam que empresas que pagam um maior valor de honorários de auditoria, tendem a receber seus pareceres em menor tempo. Assim, espera-se uma relação negativa entre ARL e LnTAUDFEES, uma vez que, conforme Camargo (2012), honorários mais altos podem estar relacionados a maior acompanhamento da empresa auditada pelos auditores. Isto acarreta, consequentemente, na maior confiabilidade dos controles implantados, que pode implicar na redução do tempo para a emissão do parecer.

\section{ANÁLISE E RESULTADOS}

\subsection{ESTATÍSTICA DESCRITIVA E ANÁLISE UNIVARIADA}

A Tabela 1 apresenta informações sobre as firmas de auditoria com expertise nos setores investigados, seguido das estatísticas descritivas para as variáveis estudadas no Painel B e C.

Tabela 1: Estatísticas descritivas

\begin{tabular}{|c|c|c|c|c|c|}
\hline \multicolumn{6}{|c|}{ Painel A: Firmas de auditoria com expertise no setor } \\
\hline Setor & SPC10 & SPC30 & Setor & SPC10 & SPC30 \\
\hline Água e Saneamento & DTT & DTT & $\begin{array}{l}\text { Petróleo, Gás e } \\
\text { Biocombustiveis }\end{array}$ & PWC & PWC \\
\hline $\begin{array}{c}\text { Alimentos } \\
\text { Processados }\end{array}$ & NENHUMA & PWC & $\begin{array}{l}\text { Prod. Uso Pessoal e } \\
\text { Limpeza }\end{array}$ & E\&Y & E\&Y \\
\hline Comércio & $E \& Y$ & E\&Y & Programas e Serviços & NENHUMA & KPMG; PWC \\
\hline $\begin{array}{l}\text { Comércio e } \\
\text { Distribuição }\end{array}$ & DTT & DTT & Químicos & PWC & PWC \\
\hline $\begin{array}{l}\text { Construção e } \\
\text { Engenharia }\end{array}$ & KPMG & KPMG & Saúde & NENHUMA & DTT; E\&Y \\
\hline $\begin{array}{l}\text { Diversos/Consumo } \\
\text { Cíclico } \\
\end{array}$ & NENHUMA & DTT; PWC & Serviços & KPMG & KPMG \\
\hline $\begin{array}{l}\text { Diversos-Consumo } \\
\text { Nâo Cíclico }\end{array}$ & KPMG & KPMG & $\begin{array}{l}\text { Siderurgia e } \\
\text { Metalurgia }\end{array}$ & PWC & PWC \\
\hline Energia Elétrica & PWC & PWC; DTT & $\begin{array}{c}\text { Tecidos, Vestuário e } \\
\text { Calçados }\end{array}$ & E\&Y & E\&Y \\
\hline Madeira e Papel & PWC & PWC & Telefonia Fixa & KPMG & KPMG \\
\hline $\begin{array}{c}\text { Máquinas e } \\
\text { Equipamentos }\end{array}$ & NENHUMA & E\&; KPMG & Telefonia Móvel & PWC & PWC \\
\hline $\begin{array}{l}\text { Material de } \\
\text { Transporte }\end{array}$ & KPMG & KPMG & Transporte & PWC & PWC \\
\hline Mineração & PWC & PWC & & & \\
\hline \multicolumn{6}{|c|}{ Painel B: Estatistica descritiva das variáveis numéricas } \\
\hline Variáveis & $\mathrm{N}$ & Mínimo & Máximo & Média & Desvio Padrão \\
\hline ARL & 72 & 27 & 86 & 60 & 15 \\
\hline REC & 72 & $4.395,00$ & $304.889 .934,00$ & $15.534 .566,04$ & $39.101 .666,84$ \\
\hline LnREC & 72 & 8,3882 & 19,5355 & 15,4654 & 1,5430 \\
\hline LIQC & 72 & 0,5454 & 5,4951 & 1,9233 & 0,9224 \\
\hline LnLIQC & 72 & $-0,6063$ & 1,7039 & 0,5571 & 0,4345 \\
\hline TAUDFEES & 72 & $30.500,00$ & $22.048 .000,00$ & $2.881 .638,18$ & $4.208 .591,65$ \\
\hline LnTAUDFEES & 72 & 10,3255 & 16,9087 & 14,1733 & 1,2086 \\
\hline
\end{tabular}




\begin{tabular}{|c|c|c|}
\hline \multicolumn{2}{|c|}{ Painel C: Estatística descritiva das variáveis dummy } \\
\hline Variáveis & $\mathrm{N}$ & Proporção de Dummy = 1 (\%) \\
\hline SPEC10 & 20 & 27,8 \\
\hline SPEC30 & 35 & 48,6 \\
\hline LOSS & 12 & 16,7 \\
\hline CONTR & 7 & 9,7 \\
\hline SUB & 67 & 93,1 \\
\hline TEN & 14 & 19,4 \\
\hline COMIT & 27 & 37,5 \\
\hline END & 72 & 100,0 \\
\hline MODIF & 72 & 0 \\
\hline
\end{tabular}

Legenda: DTT - Deloitte Touche Tohmatsu Auditores Independentes; PWC - Pricewaterhousecoopers Auditores Independentes; KPMG - KPMG Auditores Independentes; E\&Y - Ernst \& Young Terco Auditores Independentes S.S. Nota: Conforme definição (1) e (2) da seção 3.2, respectivamente, SPC10: a firma de auditoria possui expertise no setor se tem a maior quota de mercado nos respectivos setores e se a sua quota de mercado é, pelo menos, dez pontos percentuais, maior do que a da segunda colocada; e SPC30: a firma de auditoria possui expertise no setor se possuir uma quota de mercado superior a $30 \%$ nos respectivos setores.
Fonte: Elaborada pelos autores.

Algumas observações podem ser extraídas da Tabela 1. A Pricewaterhousecoopers Auditores Independentes é a firma de auditoria que possui expertise em mais setores dos investigados. São nove setores dentre os vinte e três, considerando SPEC10. A KPMG Auditores Independentes possui expertise em seis setores (SPEC10). O número médio de dias para o recebimento do parecer de auditoria para as empresas da amostra é de 60 dias. Cerca de $30 \%$ da amostra é auditada por auditores especialistas no setor (SPEC10) e 48,6\% são auditadas por firmas de auditoria que possuem mais de $30 \%$ dos honorários pagos pelas empresas do setor (SPEC30). Doze empresas da amostra (16,7\%) apresentaram prejuízos em 2013 e 9,7\% possuem controle governamental. Todas as empresas da amostra têm encerramento contábil em 31/12 e nenhuma delas recebeu parecer modificado no período. Por esta razão, estas duas variáveis não puderam ser utilizadas na análise de regressão.

Em uma análise adicional, observou-se que, dentre os setores nos quais as firmas de auditoria possuem expertise é possível identificar diferentes sócios responsáveis pelas auditorias, o que denota que, ainda que as auditorias sejam realizadas pela mesma firma, há uma separação entre as equipes envolvidas na auditoria de cada setor. Esta observação auxilia na averiguação da validade da proxy utilizada para mensuração da expertise.

Com o intuito de obtenção de um panorama inicial do fenômeno investigado, realizou-se uma análise univariada para compreensão do comportamento da variável dependente ARL. Este procedimento precede a realização da análise multivariada e seus fundamentos seguem a mesma linha de formulação da hipótese de pesquisa, conforme apresentado na seção "Referencial Teórico". Em outras palavras, é uma abordagem univariada do teste de hipótese. Neste sentido, na Tabela 2 é apresentada uma comparação das médias das variáveis estudadas para empresas auditadas por firmas de auditoria com expertise no setor e sem esta característica.

Tabela 2: Análise univariada para empresas auditadas por firmas com expertise versus sem expertise

\begin{tabular}{|c|c|c|c|c|c|}
\hline \multirow{3}{*}{ Variáveis } & \multicolumn{5}{|c|}{ SPEC10 } \\
\hline & \multicolumn{2}{|c|}{ Empresas auditadas por firmas } & \multirow{2}{*}{$\begin{array}{l}\text { Diferença a } \\
\text { de média }\end{array}$} & \multirow{2}{*}{ Teste t } & \multirow{2}{*}{ Sig. (2-tailed) } \\
\hline & com expertise & sem expertise & & & \\
\hline ARL & 52 & 63 & $-10,377$ & $-2,701$ & 0,009 \\
\hline LnREC & 16,50 & 15,07 & 1,433 & 3,860 & 0,000 \\
\hline LnLIQC & 0,44 & 0,60 & $-0,160$ & $-1,413$ & 0,162 \\
\hline LnTAUDFEES & 15,34 & 13,72 & 1,615 & 6,320 & 0,000 \\
\hline
\end{tabular}




\begin{tabular}{|c|c|c|c|c|c|}
\hline \multirow{3}{*}{ Variáveis } & \multicolumn{5}{|c|}{ SPEC30 } \\
\hline & \multicolumn{2}{|c|}{ Empresas auditadas por firmas } & \multirow{2}{*}{$\begin{array}{l}\text { Diferença } \\
\text { de média }\end{array}$} & \multirow{2}{*}{ Teste $t$} & \multirow{2}{*}{ Sig. (2-tailed) } \\
\hline & com expertise & sem expertise & & & \\
\hline ARL & 57 & 63 & $-5,396$ & $-1,516$ & 0,134 \\
\hline LnREC & 15,75 & 15,20 & 0,547 & 1,519 & 0,133 \\
\hline LnLIQC & 0,51 & 0,60 & $-0,085$ & $-0,825$ & 0,412 \\
\hline LnTAUDFEES & 14,85 & 13,53 & 1,320 & 5,504 & 0,000 \\
\hline
\end{tabular}

Fonte: Elaborada pelos autores.

Conforme as informações contidas na Tabela 2, observa-se que a média de ARL é menor em pelo menos dez dias para empresas auditadas por firmas com expertise e que esta diferença é significante ao nível de 1\%. Além disso, as empresas auditadas por auditores experts possuem em média maiores receitas e pagam maiores honorários totais aos seus auditores. Quando a medida considerada para expertise é SPEC30, a única variável com diferença significante entre a média dos dois grupos é o total de honorários de auditoria. Embora os resultados sobre ARL sejam consistentes com a hipótese levantada na pesquisa, na análise univariada não são controladas outras variáveis que são utilizadas na literatura para determinar ARL.

\subsection{ANÁLISE MULTIVARIADA}

Na Tabela 3 são apresentados os resultados da análise de regressão. Foram gerados três modelos. O primeiro modelo considera como variável de expertise SPEC10, o segundo considera SPEC30 e o terceiro considera todas as variáveis propostas na seção 3.2.3. Estes três modelos são apresentados, respectivamente, no Painel A, B e C, da Tabela 3.

Tabela 3: Análise de regressão dos determinantes de ARL

\begin{tabular}{|c|c|c|c|c|c|c|c|}
\hline \multicolumn{8}{|c|}{ Painel A: Modelo 1 - Com SPEC10 } \\
\hline \multicolumn{2}{|c|}{ Variáveis Independentes } & Sinal Esp. & Coeficiente & Erro Padrão & T & P-value & VIF \\
\hline \multicolumn{2}{|l|}{ Constante } & & 5,379832 & 24,744 & 0,217 & 0,829 & \\
\hline \multicolumn{2}{|l|}{ LnREC } & $(-)$ & $-1,01848$ & 1,2436 & $-0,819$ & 0,416 & 1,766 \\
\hline \multicolumn{2}{|l|}{ LnLIQC } & $(-)$ & 6,957095 & 3,7765 & 1,842 & 0,070 & 1,292 \\
\hline \multicolumn{2}{|l|}{ LOSS } & $(+)$ & 8,1286 & 4,0387 & 2,013 & 0,048 & 1,102 \\
\hline \multicolumn{2}{|l|}{ CONTR } & $(+)$ & 12,34114 & 5,2559 & 2,348 & 0,022 & 1,17 \\
\hline \multicolumn{2}{|l|}{ LnTAUDFEES } & $(-)$ & 4,853608 & 1,6608 & 2,922 & 0,005 & 1,933 \\
\hline \multicolumn{2}{|l|}{$\overline{\text { SET_CT }}$} & $?$ & 7,450156 & 3,9101 & 1,905 & 0,061 & 1,100 \\
\hline \multicolumn{2}{|l|}{ SET_MB } & $?$ & $-11,9102$ & 4,96 & $-2,401$ & 0,019 & 1,30 \\
\hline \multicolumn{2}{|l|}{ SET_TI } & $?$ & $-37,6279$ & 12,424 & $-3,029$ & 0,004 & $1,02 \varepsilon$ \\
\hline \multicolumn{2}{|l|}{ SPEC10 } & $(-)$ & $-15,2644$ & 4,1116 & $-3,712$ & 0,000 & 1,650 \\
\hline \multicolumn{8}{|l|}{ Estatísticas } \\
\hline R2 & 0,443157 & & Erro Padrão & 12,167 & $\mathrm{~F}$ & & 5,4824 \\
\hline R2 Ajustado & 0,362325 & & & & Sig. & & 0,000 \\
\hline
\end{tabular}

\begin{tabular}{|l|c|r|r|r|r|r|}
\hline \multicolumn{1}{|l|}{ Painel B: Modelo 2-Com SPEC30 } \\
\hline \multicolumn{1}{|c|}{ Variáveis Independentes } & Sinal Esp. & \multicolumn{1}{c|}{ Coeficiente } & \multicolumn{1}{c|}{ Erro Padrão } & \multicolumn{1}{c|}{ T } & \multicolumn{1}{c|}{ P-value } & \multicolumn{1}{c|}{ VIF } \\
\hline Constante & & 36,92902 & 25,051 & 1,474 & 0,146 & \\
\hline LnREC & $(-)$ & $-1,87589$ & 1,3675 & $-1,372$ & 0,175 & 1,813 \\
\hline LnLIQC & $(-)$ & 7,270233 & 4,1024 & 1,772 & 0,081 & 1,294 \\
\hline LOSS & $(+)$ & 7,473999 & 4,4466 & 1,681 & 0,098 & 1,134 \\
\hline CONTR & $(+)$ & 11,09911 & 5,6893 & 1,951 & 0,056 & 1,173 \\
\hline
\end{tabular}




\begin{tabular}{|c|c|c|c|c|c|c|c|}
\hline \multicolumn{2}{|l|}{ LnTAUDFEES } & $(-)$ & 3,531619 & 1,9203 & 1,839 & 0,071 & 2,194 \\
\hline \multicolumn{2}{|l|}{ SET_CT } & $?$ & 4,670181 & 4,3181 & 1,082 & 0,284 & 1,139 \\
\hline \multicolumn{2}{|l|}{ SET_MB } & $?$ & $-14,4676$ & 5,3845 & $-2,687$ & 0,009 & 1,310 \\
\hline \multicolumn{2}{|l|}{ SET_TI } & $?$ & $-32,7608$ & 13,603 & $-2,408$ & 0,019 & 1,047 \\
\hline \multicolumn{2}{|l|}{ SPEC30 } & $(-)$ & $-6,13591$ & 4,0019 & $-1,533$ & 0,130 & 1,652 \\
\hline \multicolumn{8}{|l|}{ Estatísticas } \\
\hline $\mathrm{R} 2$ & 0,344236 & \multicolumn{2}{|r|}{ Erro Padrão } & 13,203 & $\mathrm{~F}$ & \multicolumn{2}{|l|}{3,616248} \\
\hline R2 Ajustado & 0,249045 & & & Sig. & 0,001 & & \\
\hline
\end{tabular}

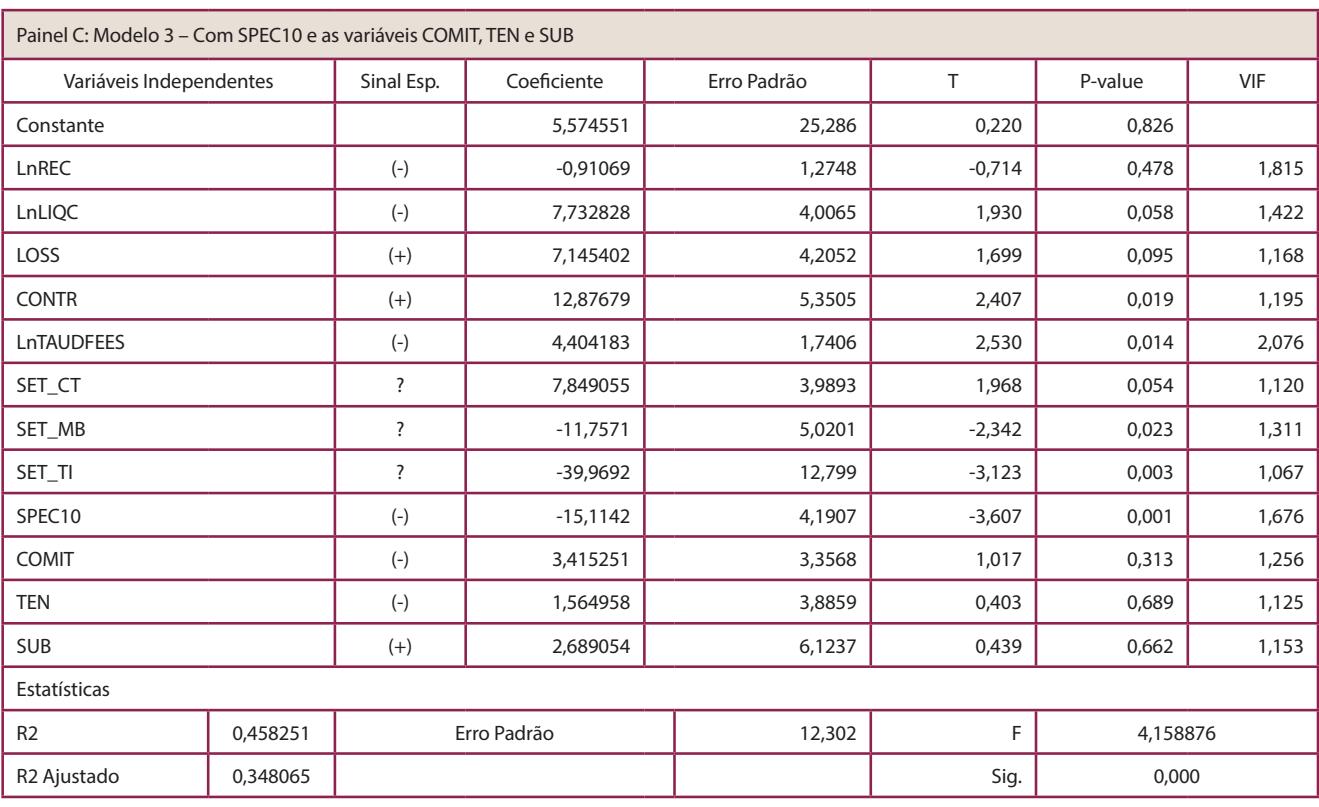

Fonte: Elaborada pelos autores.

Ambos os modelos são significativos em conjunto. O modelo com maior valor explicativo foi o Modelo 1, com R2 ajustado de 36,2\%. A variável SPEC30, utilizada no modelo 2 para expertise, não foi significativa. $O$ resultado do modelo 2 pode indicar que para as empresas analisadas, a medida de expertise SPEC10 reflete melhor a realidade das empresas brasileiras. No modelo 3, foram incluídas as variáveis COMIT, TEN e SUB. Todavia, nenhuma delas apresentou relação significativa com ARL.

Algumas considerações podem ser realizadas em relação a estas variáveis que não foram significativas:

- A variável COMIT apresentou uma relação negativa com ARL, como esperado inicialmente na pesquisa, implicando que empresas que possuem um comitê de auditoria constituído tendem a possuir um menor ARL. A literatura aponta que uma sólida estrutura de governança corporativa pode auxiliar a mitigar a pressão exercida pelos gestores sobre os auditores e auxiliar na redução de problemas relacionados à auditoria (Ballesta \& García-Meca, 2005) de modo que empresas com comitês de auditoria constituídos poderiam ter ARL's menores. Contudo, esta relação não foi significativa como constatado no estudo de Camargo (2012), possivelmente em decorrência do período e amostra investigada serem diferentes desta pesquisa - Camargo (2012) investigou dados de 2010 de todas as empresas não-financeiras listadas na BM\&FBovespa - isto pode ter influenciado os resultados. Outra questão que pode ser considerada é a efetividade da atuação dos comitês de auditoria no Brasil, que por questões culturais, temporais ou regulatórias possam ter influenciado na significância não observada na pesquisa. De forma específica, comitês de auditoria pro forma, constituídos com objetivo de atender apenas a práticas cerimoniais, como diminuir o tempo do rodízio de auditoria ou dar sensação confiança para 
investidores e demais stakeholders, apesar de presentes na estrutura de governança das empresas podem estar vinculados a práticas não efetivas de governança.

- A variável TEN foi baseada nos estudos de Habib e Bhuiyan (2011), Lee et al. (2009) e Mai e Trung (2014), desenvolvidos em outros países. Seguindo as expectativas iniciais da pesquisa, a variável apresentou uma relação negativa com ARL, indicando que empresas com tempo de relacionamento maior com a firma de auditoria tendem a apresentar menores ARL's. Contudo, esta relação não foi significativa, similar ao encontrado por Camargo (2012) para empresas brasileiras. Uma questão que pode influenciar esta relação é que no Brasil temos a obrigatoriedade de rodízio entre as firmas de auditoria para empresas de capital aberto, fato que pode influenciar no tempo de relacionamento entre a firma de auditoria e a empresa auditada. Vale salientar, que da amostra investigada apenas quatorze empresas apresentaram um TEN acima de três anos.

- A variável SUB também foi baseada em estudos internacionais - Ashton et al. (1987), Habib e Bhuiyan (2011) e Ng e Tai (1994) - em que foi encontrada como significativa nos dois últimos para reduzir o ARL. Nesta pesquisa, apesar de a variável ter apresentado uma relação positiva com ARL (Tabela 3, Painel C) em linha com o discutido na literatura anterior, uma possível justificativa para não apresentar uma relação significativa, pode ser encontrada na Tabela 1, em que 93\% das empresas da amostra possuem subsidiárias, assim, como é uma característica comum na amostra, ou seja, com baixa capacidade discriminante, não contribuiu para explicar variações no comportamento do ARL.

Neste sentido, adotou-se para análise o Modelo 1, expresso na Equação 3.

$$
\begin{aligned}
& \mathrm{ARL}=5,38-1,02 \times \mathrm{LnREC}+6,96 \times \mathrm{LnLIQC}+4,85 \times \mathrm{LnTAUDFEES}+8,13 \times \mathrm{LOSS}+ \\
& 12,34 \times \mathrm{CONTR}+7,45 \times \mathrm{SET} \_\mathrm{CT}-11,91 \times \mathrm{SET} \_\mathrm{MB}-37,63 \times \mathrm{SET} \_\mathrm{TI}-15,26 \times \mathrm{SPEC}+\varepsilon,
\end{aligned}
$$

Conforme os resultados do Modelo 1, empresas auditadas por auditores com expertise no setor têm o tempo médio para receber o parecer de auditoria diminuído em pelo menos 15 dias. Este resultado é significativo ao nível de $1 \%$ e suporta $\mathrm{H} 1$ de que empresas auditadas por firmas com expertise possuem um menor ARL. Este resultado é consistente com o encontrado por Habib e Bhuiyan (2011) na Nova Zelândia e por Mai e Trung (2014), utilizando empresas disponíveis na base de dados Compustat. Para Habib e Bhuiyan (2011), neste caso o ARL é possivelmente reduzido, pois auditores experts, em geral, possuem um sólido conhecimento do setor, e isto proporciona a eles uma maior agilidade para resolver problemas complexos, para se familiarizar com os sistemas de relatórios financeiros e de controles internos.

Com relação às variáveis de controle utilizadas, os resultados do Modelo 1 apontam que o ARL tende a ser menor para empresas maiores (LnREC). Este resultado é consistente com estudos de Habib e Bhuiyan (2011), Mai e Trung (2014), Newton e Ashton (1989), Ng e Tai (1994) e Pereira e Costa (2012). Uma possível explicação para que empresas maiores apresentem ARL menores é a de que possuam sistemas de relatórios mais estruturados, controles mais eficazes, razão esta que proporcionaria a realização da auditoria em um tempo menor.

Empresas que pertencem ao setor de materiais básicos (SET_MB) e de tecnologia da informação (SET_TI) também apresentaram, em média, ARLs menores do que as demais, 11 e 37 dias, em média, respectivamente. Isto pode ser justificado, em parte, pelas características inerentes a cada setor. Por exemplo, empresas do setor de tecnologia da informação tendem a utilizar maior tecnologia no proces- 
samento de dados e nos seus controles internos, características que podem diminui o tempo utilizado durante o trabalho da firma de auditoria.

As empresas com prejuízos (LOSS) demoram, em média, oito dias a mais para receber seu parecer que outras sem esta característica. Estes resultados são consistentes com os trabalhos de Camargo (2012), Habib e Bhuiyan (2011), Lee et al. (2009), Mai e Trung (2014) e Pereira e Costa (2012). Empresas que apresentam prejuízo no período têm maior propensão a querer retardar esta má notícia (Habib \& Bhuiyan, 2011), além de possuírem maior risco de entrarem em processo de descontinuidade, o que pode deixar os auditores mais cautelosos para a emissão do parecer (Ireland, 2003).

Foram encontrados também ARLs maiores para empresas com maiores índices de liquidez corrente (LnLIQC). Esta constatação vai de encontro com as expectativas da pesquisa, de que a relação entre as duas variáveis seria inversa, conforme encontrado por Camargo (2012). Uma possível explicação para este fato é mencionada por Ireland (2003), de que altos índices de liquidez podem significar uma possível superavaliação de ativos, de forma que os auditores possam tomar maiores precauções nesta situação, retardando a emissão do relatório.

Outras variáveis que contribuem para aumentar o ARL é o fato de a empresa possuir controle governamental (CONTR) e pertencer ao setor de construção e transporte (SET_CT). Para as empresas que possuem controle governamental o ARL aumenta em 12 dias. Estes resultados são consistentes ao encontrado por Camargo (2012). Como mencionado pelo autor, em empresas com controle público, a contratação dos auditores independentes é realizada levando em consideração procedimentos formais e complexos, como a lei de licitação. Neste caso, uma possibilidade é que os auditores não se sintam pressionados como quando estão auditando empresas privadas para emitir o parecer em tempo menor, primeiro pela menor pressão exercida pela administração, e segundo, por possuírem um contrato de prestação de serviços por um tempo determinado com possibilidade praticamente remota de rescisão. Uma questão, que deve ser avaliada, se estas hipóteses forem verdadeiras, é a de que um maior tempo para emissão do parecer ocasionado por estes fatores, pode prejudicar o papel da contabilidade de diminuir a assimetria da informação e melhorar a eficiência dos mercados.

O ARL foi maior também para as empresas com maiores honorários pagos aos auditores (LnTAUDFEES). Este resultado contraria o encontrado por Leventis et al. (2005) e a expectativa inicial da pesquisa. Uma possível explicação para este resultado é a de que o total de honorários cobrados esteja relacionado a um maior número de horas de trabalho dos auditores e a uma maior complexidade na auditoria realizada, fato que implicaria em maior tempo para a conclusão da mesma.

\section{ANÁLISE DE SENSIBILIDADE}

Esta seção apresenta os resultados dos testes de análise de sensibilidade realizados para fundamentar os principais resultados da pesquisa. Primeiramente, considerando que a variável ARL é truncada à esquerda e pode ser truncada também à direita, já que as empresas constituídas sob a forma de sociedade anônima possuem um prazo máximo para a realização da Assembleia Geral Ordinária (AGO), e consequentemente, para divulgação das demonstrações financeiras, foi empregada a estimação Tobit para mitigar o risco de o estimador MQO não ser o mais indicado. Os resultados desta estimação são apresentados na Tabela 4. 
Tabela 4: Análise TOBIT dos determinantes de ARL

\begin{tabular}{|c|c|c|c|c|}
\hline \multicolumn{5}{|l|}{ Painel A: Modelo 1 - Com SPEC10 } \\
\hline Variáveis Independentes & Coeficiente & Erro Padrão & z & P-value \\
\hline Constante & 5,37983 & 22,962 & 0,234 & 0,815 \\
\hline LnREC & $-1,01848$ & 1,154 & $-0,883$ & 0,378 \\
\hline LnLIQC & 6,9571 & 3,5044 & 1,985 & 0,047 \\
\hline LOSS & 8,1286 & 3,7477 & 2,169 & 0,030 \\
\hline CONTR & 12,3411 & 4,8773 & 2,530 & 0,011 \\
\hline LnTAUDFEES & 4,85361 & 1,5412 & 3,149 & 0,002 \\
\hline SET_CT & 7,45016 & 3,6284 & 2,053 & 0,040 \\
\hline SET_MB & $-11,9102$ & 4,6027 & $-2,588$ & 0,010 \\
\hline SET_TI & $-37,6279$ & 11,529 & $-3,264$ & 0,001 \\
\hline SPEC10 & $-15,2644$ & 3,8154 & $-4,001$ & 0,000 \\
\hline \multicolumn{5}{|l|}{ Estatísticas } \\
\hline Qui-quadrado & 57,300 & P-value & 0,000 & \\
\hline Log da verossimilhança & $-276,687$ & \multicolumn{2}{|c|}{ Critério de Akaike } & 575,374 \\
\hline Critério de Schwarz & 600,417 & \multicolumn{2}{|c|}{ Critério Hannan-Quinn } & 585,344 \\
\hline
\end{tabular}

\begin{tabular}{|c|c|c|c|c|}
\hline \multicolumn{5}{|l|}{ Painel B: Modelo 2 - Com SPEC30 } \\
\hline Variáveis Independentes & Coeficiente & Erro Padrão & $z$ & P-value \\
\hline Constante & 36,929 & 23,247 & 1,589 & 0,112 \\
\hline LnREC & $-1,87589$ & 1,269 & $-1,478$ & 0,139 \\
\hline LnLIQC & 7,27023 & 3,8068 & 1,910 & 0,056 \\
\hline LOSS & 7,474 & 4,1263 & 1,811 & 0,070 \\
\hline CONTR & 11,0991 & 5,2795 & 2,102 & 0,036 \\
\hline LnTAUDFEES & 3,53162 & 1,782 & 1,982 & 0,048 \\
\hline SET_CT & 4,67018 & 4,007 & 1,166 & 0,244 \\
\hline SET_MB & $-14,4676$ & 4,9966 & $-2,895$ & 0,004 \\
\hline SET_TI & $-32,7608$ & 12,623 & $-2,595$ & 0,010 \\
\hline SPEC30 & $-6,13591$ & 3,7136 & $-1,652$ & 0,099 \\
\hline \multicolumn{5}{|l|}{ Estatísticas } \\
\hline Qui-quadrado & 37,796 & \multicolumn{2}{|l|}{ P-value } & 0,000 \\
\hline Log da verossimilhança & $-282,574$ & \multicolumn{2}{|c|}{ Critério de Akaike } & 587,147 \\
\hline Critério de Schwarz & 612,191 & \multicolumn{2}{|c|}{ Critério Hannan-Quinn } & 597,117 \\
\hline
\end{tabular}

\begin{tabular}{|l|r|r|r|r|}
\hline \multicolumn{1}{|c|}{ Painel C: Modelo 3 - Com SPEC10 e as variáveis COMIT, TEN e SUB Independentes } & \multicolumn{1}{c|}{ Coeficiente } & \multicolumn{1}{c|}{ Erro Padrão } & \multicolumn{1}{c|}{ z } & P-value \\
\hline Constante & 5,57455 & 22,89 & 0,244 & 0,808 \\
\hline LnREC & $-0,91069$ & 1,154 & $-0,789$ & 0,430 \\
\hline LnLIQC & 7,73283 & 3,6268 & 2,132 & 0,033 \\
\hline LOSS & 7,1454 & 3,8067 & 1,877 & 0,061 \\
\hline CONTR & 12,8768 & 4,8435 & 2,659 & 0,008 \\
\hline LnTAUDFEES & 4,40418 & 1,5757 & 2,795 & 0,005 \\
\hline SET_CT & 7,84906 & 3,6112 & 2,174 & 0,030 \\
\hline SET_MB & $-11,7571$ & 4,5443 & $-2,587$ & 0,010 \\
\hline SET_TI & $-39,9692$ & 11,586 & $-3,450$ & 0,001 \\
\hline SPEC10 & $-15,1142$ & 3,7936 & $-3,984$ & 0,000 \\
\hline COMIT & 3,41525 & 3,0387 & 1,124 & 0,261 \\
\hline TEN & 1,56496 & 3,5177 & 0,445 & 0,656 \\
\hline SUB & 2,68905 & 5,5433 & 0,485 & 0,628 \\
\hline Estatísticas & & & & 0,000 \\
\hline Qui-quadrado & 60,903 & P-value & & \\
\hline
\end{tabular}




\begin{tabular}{|l|r|l|r|}
\hline Log da verossimilhança & $-275,6977$ & Critério de Akaike & 579,395 \\
\hline Critério de Schwarz & 611,269 & Critério Hannan-Quinn & 592,084 \\
\hline
\end{tabular}

Fonte: Elaborada pelos autores

Na Tabela 4 é possível observar que os parâmetros dos modelos apresentados com a estimação Tobit são similares aos da Tabela 3 realizados com a estimação MQO. Algumas diferenças que podem ser destacadas estão relacionadas a melhoria na significância de algumas variáveis. Por exemplo, no Painel A - Modelo 1 observou uma melhoria na significância da variável LnLIQC. No Painel B - Modelo 2 a variável SPEC30 que anteriormente não demonstrou-se significativa (estimação MQO), nesta estimação é significante ao nível de 10\%. Esta melhoria na significância também ocorre nas variáveis do Painel C - Modelo 3, contudo sem alcançar as variáveis COMIT, TEM e SUB. Neste caso, é possível observar que os resultados apresentados na seção anterior com a estimação MQO são similares à estimação Tobit, mantendo-se válidas as análises realizadas anteriormente.

Outra análise realizada foi a utilização da regressão quantílica considerando a mediana para estimar os resultados com a inclusão do outlier excluído anteriormente devido à discrepância no valor do ARL, como mencionado na seção 3.1. Estimações realizadas (não apresentadas no corpo deste artigo) para fins de averiguação quanto aos efeitos da consideração ou não do outlier sustentam os resultados anteriormente divulgados. Em outras palavras, a eliminação da observação em questão não alterou os coeficientes e a significância das variáveis explicativas analisadas.

Adicionalmente, na Tabela 5 é apresentada a comparação entre as estimações realizadas por MQO e a regressão quantílica. Tal comparação possibilitou identificar se existem possíveis diferenças no comportamento das variáveis explicativas em relação aos diferentes quantis $(0,25 ; 0,50 ; 0,75)$ da variável dependente ARL.

Na Tabela 5 é possível observar que as variáveis explicativas seguem a mesma relação estimada com MQO, mesmo quando considerados diferentes quantis. Eventuais diferenças foram encontradas na força dos coeficientes das variáveis explicativas e na mudança de significância de algumas variáveis. Por exemplo, a variável LnREC passa a ser significativa na regressão quantílica que considera o quantil 0,25 . O impacto da expertise das firmas de auditoria é maior para empresas com um ARL maior, como pode ser observado na regressão quantílica com o quantil 0,75.

Tabela 5: Comparação entre a análise por MQO e RQ dos determinantes de ARL

\begin{tabular}{|c|c|c|c|c|}
\hline Variáveis Independentes & MQO & $\begin{array}{c}\mathrm{RQ} \\
0,25\end{array}$ & $\begin{array}{c}\mathrm{RQ} \\
0,50\end{array}$ & $\begin{array}{c}\mathrm{RQ} \\
0,75\end{array}$ \\
\hline \multirow{2}{*}{ Constante } & 5,380 & 17,222 & 12,546 & 9,798 \\
\hline & $(24,744)$ & $(22,001)$ & $(22,067)$ & $(16,215)$ \\
\hline \multirow{2}{*}{ LnREC } & $-1,018$ & $-2,370^{* *}$ & $-1,287$ & $-1,019$ \\
\hline & $(1,244)$ & $(1,106)$ & $(1,109)$ & $(0,815)$ \\
\hline \multirow{2}{*}{ LnLIQC } & $6,957^{*}$ & 3,942 & $9,668^{* * *}$ & $6,274^{* *}$ \\
\hline & $(3,776)$ & $(3,358)$ & $(3,368)$ & $(2,475)$ \\
\hline \multirow{2}{*}{ LOSS } & $8,129^{* *}$ & $11,683^{* * *}$ & $10,095^{* * *}$ & 2,698 \\
\hline & $(4,039)$ & $(3,591)$ & $(3,602)$ & $(2,647)$ \\
\hline \multirow{2}{*}{ CONTR } & $12,341^{* *}$ & $10,766^{* *}$ & $15,804^{* * *}$ & $19,079^{* * *}$ \\
\hline & $(5,256)$ & $(4,673)$ & $(4,687)$ & $(3,444)$ \\
\hline \multirow{2}{*}{ LnTAUDFEES } & $4,854^{* * *}$ & $5,120^{* * *}$ & $4,476^{* * *}$ & $5,296^{* * *}$ \\
\hline & $(1,661)$ & $(1,477)$ & $(1,481)$ & $(1,088)$ \\
\hline \multirow{2}{*}{ SET_CT } & $7,450^{* *}$ & $7,963^{* *}$ & $12,361^{* * *}$ & $5,643^{* *}$ \\
\hline & $(3,910)$ & $(3,477)$ & $(3,487)$ & $(2,562)$ \\
\hline \multirow{2}{*}{ SET_MB } & $-11,910^{* *}$ & $-7,282$ & $-11,775^{* * *}$ & $-12,725^{* * *}$ \\
\hline & $(4,960)$ & $(4,410)$ & $(4,423)$ & $(3,250)$ \\
\hline
\end{tabular}




\begin{tabular}{|l|r|r|r|r|}
\hline \multirow{2}{*}{ SET_TI } & $-37,628^{* * *}$ & $-31,001^{* * *}$ & $-38,275^{* * *}$ & $-47,528^{* * *}$ \\
\cline { 2 - 5 } & $(12,424)$ & $(11,047)$ & $(11,080)$ & $(8,141)$ \\
\hline \multirow{2}{*}{ SPEC10 } & $-15,264^{* * *}$ & $-12,983^{* * *}$ & $-14,823^{* * *}$ & $-19,373^{* * *}$ \\
\cline { 2 - 5 } & $(4,112)$ & $(3,656)$ & $(3,667)$ & $(2,694)$ \\
\hline
\end{tabular}

Legenda: MQO - Mínimos Quadrados Ordinários; RQ - Regressão Quantílica; *Significante ao nível de 10\%; **Significante ao nível de 5\%; ***Signi

A comparação apresentada para o modelo 1 que considera SPEC10, também foi realizada para o modelo 2 que contempla SPEC30 e para modelo 3 que inclui além de SPEC10 as variáveis COMIT,TEN e SUB (estimações não apresentadas no corpo deste artigo). Da mesma forma que ocorreu com o Modelo 1 , as variáveis explicativas estimadas pela regressão quantílica seguem a mesma relação apresentada pela estimação realizada com MQO (Tabela 3), com eventuais diferenças na força dos coeficientes em decorrência dos quantis considerados. Vale mencionar que a variável SPEC30, modelo 2, apresenta-se significativa ao nível de $1 \%$ quando considerado o quantil 0,25. Já as variáveis COMIT, TEN e SUB, Modelo 3, não apresentaram-se significativas em nenhum dos modelos estimados, seguindo a tendência dos resultados apresentados pela estimação MQO. Em geral, é possível identificar com estas estimações adicionais que os resultados apresentados na seção 4 são robustos e as análises realizadas são válidas.

\section{CONSIDERAÇÕES FINAIS}

A presente pesquisa buscou responder a seguinte questão: Qual a relação entre o ARL e a expertise da firma de auditoria no setor auditado? Neste sentido, seu objetivo foi identificar se as empresas auditadas por uma firma de auditoria com expertise no setor auditado possuem um ARL menor do que o das demais. Este objetivo foi atendido por meio de uma análise de regressão múltipla com uma amostra formada por empresas do índice IBrX100 da BM\&FBOVESPA. Os resultados apontaram que a expertise da firma de auditoria no setor é capaz de diminuir consideravelmente o ARL, quando comparado com empresas auditadas por firmas sem esta característica, possuindo neste caso uma relação negativa, ou seja, empresas auditadas por firmas com expertise tendem a apresentar menor ARL. Este resultado não suporta a rejeição de H1. Como discutido anteriormente, isto possivelmente está relacionado ao fato de firmas de auditoria com expertise possuírem um sólido conhecimento no setor, implicando em maior agilidade na resolução de problemas encontrados durante a auditoria e também para se familiarizar ao sistema de relatórios financeiros e aos controles internos adotados pelas empresas auditadas. Este resultado merece atenção, pois menores ARLs implicam em demonstrações contábeis divulgadas em tempo mais oportuno aos usuários, contribuindo para melhorar a eficiência dos mercados.

Contrariando o encontrado em pesquisas anteriores, algumas variáveis apresentaram relação inversa à esperada com o ARL. É o caso das variáveis LnLIQC e LnTAUDFEES. Possíveis explicações foram discutidas na seção anterior, contudo deve-se reconhecer que estes resultados podem ser decorrentes da amostra, período e ambiente legal que o estudo foi desenvolvido. É necessário que novas investigações sejam realizadas para se chegar a resultados mais conclusivos sobre o ARL e as variáveis mencionadas. Este também é o caso das variáveis que estavam entre as apontadas pela literatura e foram investigadas (COMIT, SUB e TEN), contudo, não apresentaram relações significativas com ARL. Cabe destacar, que por algumas destas variáveis apresentarem-se significativas em pesquisas anteriores, inclusive no Brasil, por exemplo, a variável COMIT foi significativa para explicar o ARL no estudo de Camargo (2012), estas devem continuar sendo investigadas. Para COMIT, é possível que além da consideração de ter ou não 
o comitê de auditoria, poderiam ser avaliadas outras caraterísticas como proxies para a efetividade do mesmo, como o número de membros ou a expertise financeira destes membros.

Outra variável que merece ser investigada em pesquisas posteriores é o controle governamental (CONTR), que em linha com pesquisas anteriores realizadas no Brasil foi significativa também neste estudo.

É necessário destacar que os resultados desta pesquisa podem ter implicações práticas. É possível que as empresas concentrem seus esforços na contratação de auditores com expertise, uma vez que esta característica, condizente com os resultados encontrados neste estudo, possa contribuir para diminuição do ARL e consequentemente para um tempo menor na publicação das demonstrações contábeis. Isto pode ser visto pelos agentes do mercado e demais stakeholders interessados em informações sobre a empresa como um fator positivo, uma vez que implica em maior agilidade na prestação de informações. Cabe salientar que a tempestividade é uma das características qualitativas da informação contábil, segundo a estrutura conceitual para elaboração de relatórios contábeis. Os resultados também podem ser úteis para normatizadores, como um possível atenuante para as características negativas relacionadas ao rodízio de auditoria, que pode aumentar o ARL.

Recomenda-se que outras pesquisas sejam realizadas sobre o tema investigado, de modo, a verificar se com amostras diferentes, os resultados se comportam de forma similar ao encontrado nesta pesquisa. Por se tratar de uma investigação inicial sobre a existência de relação entre a expertise e a diminuição do ARL, optou-se pela investigação com dados de corte, contudo, é relevante que futuramente, resultados de pesquisas realizadas com dados em painel sejam comparados aos encontrados nesta pesquisa. Adicionalmente, outras proxies para expertise poderiam ser testadas, bem como outras variáveis que contribuam para diminuir o ARL. Em virtude de a proxy utilizada para mensuração da expertise envolver o valor dos honorários recebidos pelas firmas de auditoria, pode-se questionar se a diminuição do ARL está atrelada realmente a expertise dos auditores ou ao volume pago de honorários pelas empresas. Conclusões a este respeito ainda não são pacíficas na literatura. Contudo, não se pode desconsiderar que, assim como sustentado pela literatura, maiores valores de honorários estão estreitamente relacionados à complexidade da auditoria realizada, às responsabilidades assumidas pelos auditores, ao prêmio recebido pela marca sustentada pela firma, e ao montante de trabalho estimado para realizar a auditoria. Neste caso, estas questões podem ser investigadas em futuras pesquisas. Por fim, as conclusões do estudo possuem algumas limitações que devem ser consideradas. Por se tratar de uma pesquisa empírica, é possível que variáveis que contribuiriam para explicar o ARL tenham sido omitidas. A interpretação dos resultados deve considerar o período investigado e a amostra analisada.

\section{REFERÊNCIAS}

Ashton, R. H., Willingham, J. J., \& Elliott, R. K. (1987). An Empirical Analysis of Audit Delay. Journal of Accounting Research, 25(2), 275-292. doi: 10.2307/2491018

Ballesta, J. P. S., \& García-Meca, E. (2005). Audit qualifications and corporate governance in Spanish listed firms. Managerial Auditing Journal, 20(7), 725-738. doi: 10.1108/02686900510611258

Bamber, E. M., Bamber, L. S., \& Schoderbek, M. P. (1993, springer). Audit Structure and other Determinants of Audit Report Lag: An Empirical Analysis. Auditing: A Journal of Practice \& Theory, 12(1), 1-23. 
Bruynseels, L., Knechel, W. R., \& Willekens, M. (2011). Auditor Differentiation, Mitigating Management Actions, and Audit-Reporting Accuracy for Distressed Firms. Auditing: A Journal of Practice \& Theory, 30(1), 1-20. doi: 10.2308/aud.2011.30.1.1

Camargo, R. V. W. (2012). Determinantes dos pareceres dos auditores independentes emitidos às companhias negociadas na BMF\&BOVESPA. Dissertação de Mestrado em Contabilidade, Universidade Federal de Santa Catarina (UFSC), Santa Catarina, SC, Brasil.

Chambers, A. E., \& Penman, S. H. (1984). Timeliness of Reporting and the Stock Price Reaction to Earnings Announcements. Journal of Accounting Research, 22(1), 21-47. doi: 10.2307/2490700

Comitê de Pronunciamentos Contábeis. (2011). Pronunciamento Conceitual Básico (R1), de 02 de dezembro de 2011. Estrutura Conceitual para Elaboração e Divulgação de Relatório Contábil-Financeiro. Recuperado em 26 novembro, 2014, de http://www.cpc.org.br/CPC/Documentos-Emitidos/Pronunciamentos/Pronunciamento? $\mathrm{Id}=80$.

Comissão de Valores Mobiliários (1999). Instrução CVM no 308, de 14 de maio de 1999. Dispõe sobre o registro e o exercício da atividade de auditoria independente no âmbito do mercado de valores mobiliários, define os deveres e as responsabilidades dos administradores das entidades auditadas no relacionamento com os auditores independentes. Recuperado em 26 novembro, 2014, de http://www. cvm.gov.br/asp/cvmwww/atos/Atos_Redir.asp?File=linstlinst308consolid.doc.

Comissão de Valores Mobiliários (2011). Instrução CVM n 509, de 16 de novembro de 2011. Acrescenta artigos à Instrução CVM no 308, de 14 de maio de 1999, e altera artigos e anexo da Instrução CVM nº 480, de 7 de dezembro de 2009. Recuperado em 26 novembro, 2014, de http://www.cvm.gov.br/asp/ cvmwww/atos/Atos_Redir.asp?Tipo=I\&File=linst linst509.doc.

Habib, A., \& Bhuiyan, M. B. U. (2011). Audit firm industry specialization and the audit report lag. Journal of International Accounting, Auditing and Taxation, 20(1), 32-44. doi: 10.1016/j.intaccaudtax.2010.12.004

Ireland, J. C. (2003). An empirical investigation of determinants of audit reports in the UK. Journal of Business Finance and Accounting, 30(7-8), 975-1015. doi: 10.1111/1468-5957.05417

Jaggi, B., \& Tsui, J. (1999). Determinants of audit report lag: Further evidence from Hong Kong. Accounting and Business Research, 30(1), 17-28.

Jensen, M. C., \& Meckling, W. H. (1976). Theory of the firm: Managerial behavior, agency costs and ownership structure. Journal of Financial Economics, 3(4), 305-360. doi: 10.1016/0304-405X(76)90026-X

Lee, H.-Y., Mande, V., \& Son, M. (2009). Do Lengthy Auditor Tenure and the Provision of Non-Audit Services by the External Auditor Reduce Audit Report Lags? International Journal of Auditing, 13(2), 87-104. doi: 10.1111/j.1099-1123.2008.00406.x

Leventis, S., Weetman, P., \& Caramanis, C. (2005). Determinants of Audit Report Lag: Some Evidence from the Athens Stock Exchange. International Journal of Auditing, 9(1), 45-58. doi: 10.1111/j. 1099-1123.2005.00101.x 
Mai, D., \&Trung, P. (2014). Audit tenure, auditor specialization and audit report lag. Managerial Auditing Journal, 29(6), 490-512. doi: doi:10.1108/MAJ-07-2013-0906

Newton, J. D., \& Ashton, R. H. (1989). The Association Between Audit Technology and Audit Delay. Auditing-a Journal of Practice \& Theory, 8(Suppl.), 22-37.

Ng, P. P. H., \& Tai, B. Y. K. (1994). An Empirical Examination Of The Determinants Of Audit Delay In Hong Kong. The British Accounting Review, 26(1), 43-59. doi: 10.1006/bare.1994.1005

Palmrose, Z. V. (1986). Audit Fees and Auditor Size: Further Evidence. Journal of Accounting Research, 24(1), 97-110. doi: 10.2307/2490806

Pereira, A. N., \& Costa, F. M. (2012). Determinantes do Atraso de Auditoria Externa (Audit Delay) em Companhias Brasileiras. Anais do Encontro Nacional da Associação Nacional de Pós-Graduação e Pesquisa em Administração - EnANPAD,Rio de Janeiro, RJ, Brasil, 36.

Reichelt, K. J., \& Wang, D. (2010). National and office-specific measures of auditor industry expertise and effects on audit quality. Journal of Accounting Research, 48(3), 647-686. doi: 10.1111/j. 1475-679X.2009.00363.x

Watts, R. L., \& Zimmerman, J. L. (1983). Agency Problems, Auditing, and The Theory of The Firm: Some Evidence. Journal of Law \& Economics, 26(3), 613-633. doi: 10.1086/467051

Ye, P., Carson, E., \& Simnett, R. (2011). Threats to auditor independence: The impact of relationship and economic bonds. Auditing: A Journal of Practice \&Theory, 30(1), 121-148. doi: 10.2308/aud.2011.30.1.121 